\title{
Management Format in Turkey in the Pandemic; How was the Pandemic Managed in Our Hospital?
}

\author{
(D) Pelin IIlhan 1,2, (D) Hakan Gürbüz ${ }^{3}$ \\ 1 University of Health Sciences Turkey, Prof. Dr. Cemil Taş̧̧ığlu City Hospital, Department of Strategy Development, istanbul, Turkey \\ 2Sakarya University, Institute of Health Sciences, Division of Internal Diseases Nursing, Sakarya, Turkey \\ 3University of Health Sciences Turkey, Prof. Dr. Cemil Taşçıoğlu City Hospital, Responsible Manager of the Hospital, istanbul, Turkey
}

Keywords: Pandemic, COVID-19, manegement, hospital

\section{Dear Editor,}

Coronavirus Disease-2019 (COVID-19) disease was first reported in Wuhan, China's Hubei region, and spread all over the world today. It was declared as a pandemic by the World Health Organization on March 11, 2020 (1). Studies on COVID-19 in our country started on January 10 and the first meeting of the Scientific Advisory Board of the Ministry of Health was held on January 22 (2). The Ministry of Health, Provincial Health Directorate, Public Hospitals Services Presidency and District Health Directorates have provided a very serious infrastructure support by providing all logistical support, medicine and material supply for our hospital. Secondly, everyone, from healthcare personnel, cleaning worker, warehouse manager to driver in our hospital have worked in unity and solidarity with the extraordinary efforts which has provided the greatest ease in managing the pandemic process. Thirdly, the great support of our nation has ensured the smooth progress of the process. The aid campaigns organized by our people have once again revealed the unity of the Turkish nation.

To talk about the pandemic process management in our hospital, pandemic preparations started on March 4, 2020 with planning and some changes in physical conditions. We can list the changes we have made as follows:

\section{Training/Protective Measures}

Our main goal during the pandemic has been to protect our healthcare professionals. Clinical microbiology and infection diseases specialists, infection control committee nurses and training nurses gave trainings on COVID-19 precautions, the use of personal protective equipment, and hand washing to all nurses, doctors, clinical support personnel, technicians, cleaning staff and civil servants working in our hospital. Training on cleaning and disinfection control was also planned for cleaning staff. In addition to the training on COVID-19 precautions for our new staff members; orientation trainings were given by our training nurses. Three hundred and fifty people attended these trainings. None of the personnel who did not complete these trainings took an active role in the field.

\section{Pandemic Board}

In order to organize the activities in the clinic, to plan the diagnosis, treatment and follow-up of the patients with scientific methods and with a multidisciplinary perspective, the "Pandemic Board" consisting of various branches, especially the Infectious diseases and clinical microbiology clinic, was formed by the experts of our hospital, who closely followed the national and international algorithms. In addition to the infectious diseases

Address for Correspondence: Pelin Illhan, University of Health Sciences Turkey, Prof. Dr. Cemil Taşçığlu City Hospital, Department of Strategy Development, İstanbul, Sakarya University, Institute of Health Sciences, Division of Internal Diseases Nursing, Sakarya, Turkey

Phone: +90 5312711494 E-mail: basinburosu@okmeydani.gov.tr ORCID ID: orcid.org/0000-0001-9143-7512

Received: 04.06.2020 Accepted: 11.06 .2020

Cite this article as: Illhan P, Gürbüz H. Management Format in Turkey in the Pandemic; How was the Pandemic Managed in Our Hospital? Eur Arch Med Res 2020;36(Suppl 1):1-3

๑Copyright 2020 by the University of Health Sciences Turkey, Prof. Dr. Cemil Taş̧ığlu City Hospital European Archives of Medical Research published by Galenos Publishing House. 
and clinical microbiology, faculty members from internal medicine, anesthesia and reanimation, emergency medicine, family medicine, pediatrics, and clinical microbiology clinics took part in the pandemic board. Daily meetings were planned with the pandemic board. The meetings started every morning at 9:00 am and lasted about an hour and a half. The follow-up of our current patients with suspected COVID-19 was carried out by our infectious diseases and clinical microbiology clinic. With the joint decision of our pandemic board, it was decided to complete the operations planned in the first week of the pandemic and then put the surgery programs on hold, except for emergency, urgency and malignancy. In each meeting, criticisms were made about the previous days and the next was planned accordingly. It was deemed appropriate to continue Central Physician Appointment System appointments in outpatient clinics and not to see patients without an appointment throughout March. With the recommendation of the pandemic board, temperature measurement practice was initiated for patients at all outpatient clinic entrances. Except for emergency conditions, endoscopic procedures were canceled. In the first stage, those who had suspicious contact or a history of traveling abroad were accepted as patients with suspected COVID-19. As the number of patients in our country increased, every patient who came into contact with patients with suspected COVID-19, as well as who had a history of overseas travel, was considered as patient with suspected COVID-19. The pandemic board dynamically followed the process and informed all clinics about the changes. One of the most important decisions of the pandemic board was to classify and evaluate patients according to the severity of infection. Providing high-flow oxygen therapies to patients with moderate infection in the early period enabled our patients to recover faster. They facilitated the operations in our hospital with many decisions they took like this.

\section{Physical Changes}

The first physical change in our hospital, in line with COVID-19 measures, was initiated in the emergency room, where the patients with suspected COVID-19 were first admitted. Our emergency service was divided into two areas. A dirty area where patients with COVID-19 were treated and a clean area where other patients were examined, were created. The patients were guided according to whether they had COVID-19 by applying triage before being sent to these areas. Second, infectious diseases and clinical microbiology clinic was evacuated for the isolation and treatment of patients with COVID-19. As the number of our patients increased in the following days, other clinics of our hospital started to be reserved for these patients. With the increasing number of patients in the process, evacuation continued on the other floors starting from the second floor of our hospital. Likewise, necessary arrangements were initiated in our intensive care units. Anesthesia intensive care units were separated into COVID-19 intensive care units and non-covid intensive care units. At first, 8-bed anesthesia and reanimation intensive care unit, then 6-bed cardiovascular surgery intensive care unit and 17-bed anesthesia and reanimation intensive care unit were reserved for patients with COVID-19. COVID-19 intensive care units served our patients with a bed capacity of 33 in the main building of our hospital. With our 48-bed anesthesia and reanimation intensive care unit opened in our new building, our adult intensive care bed capacity reserved for patients with COVID-19 has reached 81 .

With the opening of our new hospital, 10 blocks in total were put into service for our patients with COVID-19, starting from the first block of the $7^{\text {th }}$ floor to the last block of the $6^{\text {th }}$ floor. The $6^{\text {th }}$ and $8^{\text {th }}$ floors of the main building, which were determined as clean areas, were used for all patients without COVID-19 disease who were still hospitalized and followed up in our hospital. The treatment of these patients who were hospitalized from the emergency department was carried out on these floors.

Our polymerase chain reaction (PCR) laboratory established for the COVID-19 diagnostic center on behalf of Presidency of Turkish Institutes of Health within our hospital has also facilitated the diagnosis and accelerated the treatment process.

\section{Changes in the Work Plan}

For clinics that serve patients with COVID-19, a 3-group study schedule was created until the beginning of April. One full day work and three full days rest were adopted as the basic understanding to minimize contamination with patients. Personnel planning was made in the form of a resident serving in each ward and a specialist physician on each floor. Upon the increase in patients, floor duty plans were prepared again and it was decided that one specialist physician and 3 residents for each COVID-19 ward would work under the management of Infectious diseases and clinical microbiology clinic on these floors. All our physicians, from residents to senior faculty members, worked at COVID-19 wards.

In order to strengthen the communication in the field, on-duty experts and supervisor nurses were held every morning at the COVID-19 ward, and the problems in the field were monitored instantly. The Gülbahar District Outpatient Clinic, which served 
as an additional building of our hospital, was closed with the start of the pandemic process. Our hospital's health board started a special process for our personnel with chronic health problems. Our healthcare professionals with chronic diseases were evaluated by the health board and revisions were made in the work programs of those deemed appropriate.

In order to reduce the concerns of relatives of our patients hospitalized in the COVID-19 wards during the pandemic, they were called by our residents by phone and given information.

With the increase in our intensive care bed capacity, residents and specialists from different branches were trained for anesthesia and reanimation intensive care and started to be assigned to COVID-19 intensive care units.

\section{Support Services}

One of the important actions of our hospital was the provision of personal protective equipment. Pulse oximetry and stethoscope purchases were made rapidly for the increasing needs. Rapid antibody tests were obtained and used before distributed to hospitals. PCR sampling booths and stretchers with isolation were built with institutional facilities. The dining hall arrangement was adjusted to prevent contamination. Our prediction was that we would not reach, as many countries experienced difficulties in accessing personal protective equipment such as masks for healthcare workers. For this reason, masks designed by us started to be produced from American cloth fabric, and all kinds of materials based on scientific reason were provided to protect our employees at every stage of the process. The measures regarding the visitor ban in the hospital were kept at the highest level and the field was informed on this issue. Visits of patients in intensive care units by their relatives were completely stopped when the pandemic began. Before the curfew, the discharges from the hospital were planned to be made until 12:00 in order to prevent the patients from suffering victimization, and the transfers of patients and employees were organized.

The pandemic has shown us that this is a state of mobilization. We have seen that with the support of the state organization and the nation, we can overcome any challenge. We think it will be beneficial for each hospital to develop its own strategies according to its own internal dynamics in disasters such as pandemics.

\section{Ethics}

Peer-review: Externally and internally peer-reviewed.

\section{Authorship Contributions}

Concept: P.I. H.G., Design: P.I. H.G., Ananlysis or Interpretation: H.G., Literature Search: P.I. H.G., Writing: P.I. H.G.

Conflict of Interest: No conflict of interest was declared by the authors.

Financial Disclosure: The authors declared that this study received no financial support.

\section{REFERENCES}

1. Cucinotta D, Vanelli M. WHO Declares COVID-19 a Pandemic. Acta Biomed 2020;91:157-60.

2. TC Sağlık Bakanlığı Halk Sağlığı Genel Müdürlüğü. Covid-19 (SarsCov-2 Enfeksiyonu) (Bilim Kurulu Çalıșması) Rehberi. Genel Bilgiler, Epidemiyoloji ve Tanı. Available from: URL: https://covid19.saglik.gov. tr/TR-66337/genel-bilgiler-epidemiyoloji-ve-tani.html 